\title{
Quantitative, non-invasive assessment of ventricular septal defect shunt flow by measuring proximal isovelocity surface area on colour Doppler mapping
}

\author{
Shunji Kurotobi, Tetsuya Sano, Tohru Matsushita, Makoto Takeuchi, \\ Shigetoyo Kogaki, Takashi Miwatani, Shintaro Okada
}

\begin{abstract}
Objective-To determine whether the proximal isovelocity surface area (PISA) method could be applied to estimate the magnitude of ventricular septal defect (VSD) shunt flow.

Design-Prospective analysis of clinical, echocardiographic, and angiographic data.

Setting-University hospital.

Patients-14 children with VSD.

Methods-Colour Doppler images of VSD shunt flow were obtained in parasternal long axis view, four chamber view or both, adjusted to provide the best imaging of flow. The VSD shunt flow rate and shunt volume were calculated as follows: shunt flow rate (SFR) $=2 \pi \mathbf{r}^{2}$ V/BSA in $\mathbf{m l} / \mathbf{s} / \mathbf{m}^{2}$; shunt volume $=\mathbf{S F R} \times$ shunt duration time. The shunt volume, shunt fraction, and pulmonary to systemic flow ratio (Qp:Qs) were confirmed by cardiac catheterisation.
\end{abstract}

Results-There was a correlation between shunt variables determined by PISA and those by catheterisation, including shunt volume $(r=0.78, P=0.001)$ and shunt fraction $(r=0.74, P=0.003)$. Qp:Qs was also significantly correlated with SFR $(r=0.79, P=0.0007)$. The SFR was significantly different between the four patients with Qp:Qs < 2.0 (mean (SD) 54 (33) $\mathrm{ml} / \mathrm{s} / \mathrm{m}^{2}$ ) and the 10 patients with Qp:Qs > 2.0 (186 (69) $\left.\mathrm{ml} / \mathrm{s} / \mathrm{m}^{2}\right) \quad(P=$ 0.004).

Conclusions-These data suggest that the PISA method is a reliable non-invasive investigation for the quantitative assessment of VSD shunt flow and provides important information for decisions regarding surgical repair.

(Heart 1997;78:305-309)

Keywords: ventricular septal defect; proximal isovelocity surface area; colour Doppler echocardiography

Department of Pediatrics, University Medical School, Osaka, Japan

Correspondence to: Dr Kurotobi, Department of Pediatrics, Osaka University Medical School, 2-2, Yamada-oka, Suita City, Osaka, 565 Japan.

Accepted for publication 7 May 1997 flow mapping in patients with mitral regurg tion. Previous studies have demonstrated the ability to assess regurgitant flow volume quantitatively by measuring the flow convergence area, or proximal isovelocity surface area
(PISA), in both experimental and clinical settings. ${ }^{1-6}$ PISA is not only imaged in patients with valvar regurgitation but also in patients with shunts from congenital heart diseases, especially ventricular septal defects (VSD). Recently this hydrodynamic concept has been used to develop a non-invasive method for quantitative assessment of shunt flow across a VSD. ${ }^{7}$ However, there are several potential error sources in the clinical application of PISA to shunt measurement in VSD. It is also unclear whether this non-invasive method is reliable and accurate compared with evaluation by cardiac catheterisation. The present study modified the PISA method with a shunt phase correction using a spectral Doppler echocardiogram to determine whether the method could provide precise measurements of the magnitude of shunt flow.

\section{Methods}

PATIENT SELECTION

Thirty four children with VSD were referred to our cardiology outpatient clinic between 1993 and 1994 to determine whether surgical closure was indicated. Fourteen of the 34 patients, aged 4 months to 6 years (median 11 months), subsequently underwent cardiac catheterisation to determine the need for VSD closure and formed the study group. All 14 patients had a perimembranous VSD. Digoxin or diuretics had been taken by 13 of 14 study patients.

DOPPLER COLOUR FLOW MAPPING

All 14 patients underwent Doppler colour flow mapping for assessment of VSD shunt flow using the PISA method after routine echocardiographic evaluation including cross sectional, $M$ mode, Doppler colour flow mapping, and spectral Doppler studies. Infants were sedated with triclofos sodium $(100 \mathrm{mg} / \mathrm{kg})$ for the examination. Echocardiographic examination was performed using a Hewlett Packard Sonos 1500 (Tokyo, Japan) with a 3.5 or $5 \mathrm{MHz}$ transducer. The aliasing velocity in this study with colour Doppler imaging by the PISA method ranged from 31 to $51 \mathrm{~cm} / \mathrm{s}$. The colour gain level was kept just below the point where static noise was visible in the colour signal. The frame memory function, which allows frame by frame analysis, and the zoom function were employed to obtain a high quality image of the PISA of the VSD shunt flow. The frame image of maxi- 
mum hemispheric PISA of the VSD shunt flow was obtained on the oblique four chamber view, long axis view or both in each patient.

\section{DOPPLER COLOUR FLOW MEASUREMENTS}

The PISA was defined on Doppler flow mapping as a hemispheric area of laminar flow with aliased velocities entering the restrictive orifice. The first aliasing region may be considered a hemispheric isovelocity surface. The radius of hemispheric PISA, from the border of the first colour convergence to the centre of the VSD, was measured manually (fig 1 ). The continuity equation predicts that all flow crossing this boundary, boundary of the PISA, will enter the orifice, and thus the flow velocity area along this surface should equal the instantaneous flow volume. Multiplying the area of the isovelocity hemisphere surface $\left(\mathrm{cm}^{2}\right)$ by the velocity (aliasing velocity) $(\mathrm{cm} / \mathrm{s})$ along it yields an index of flow. Therefore, it is possible to calculate the flow rate (in $\mathrm{ml} / \mathrm{s}$ ) by the following formula: flow rate $=2 \pi \mathrm{r}^{2} \mathrm{~V}$, where $r$ is the radius of hemispheric PISA and $V$ is the aliasing velocity.

\section{VSD SHUNT FLOW CALCULATIONS}

The VSD shunt flow rate (SFR) (in $\mathrm{ml} / \mathrm{s} / \mathrm{m}^{2}$ ) was obtained using the aforementioned formula indexed to body surface area. The shunt of a restrictive VSD is mostly detected during the systolic phase. The VSD shunt duration (in seconds) was measured, and VSD shunt during the systolic phase was confirmed on the spectral Doppler echocardiogram. The VSD shunt volume (in $\mathrm{ml} / \mathrm{m}^{2}$ ) was calculated using the corrected SFR and shunt duration: shunt volume $=$ SFR $\times$ shunt duration. Left ventricular end diastolic volume index (LVEDVI), left ventricular end systolic volume index (LVESVI), and left ventricular stroke volume index (LVSVI) were measured as the $M$ mode variables. The three volume characteristics were calculated by Teicholtz's equation. ${ }^{8}$ Finally, the shunt fraction (\%) by the PISA method was calculated as the shunt volume divided by the LVSVI. All measurements were an average of three consecutive beats. There was no significant difference in heart rate during measurements in any patient.

\section{CARDIAC CATHETERISATION}

Cardiac catheterisation and biplane left ventriculography was performed one or two days (mean (SD) $1.8(0 \cdot 3)$ ) after the echocardiographic examination. Premedication with pethidine hydrochloride and pentazocine was followed by mild anaesthesia with a single intravenous injection of thiopental sodium (1-1.5 mg/kg). Biplane cineangiographic left ventriculography was performed under stable haemodynamic conditions at least 60 minutes after anaesthesia. Ventricular volume was calculated by the area-length method and corrected using the regression equation derived by Dodge et al. ${ }^{9}$ The pulmonary to systemic flow ratio (Qp:Qs) and shunt fraction were calculated by Fick's rule based on estimated oxygen consumption. ${ }^{10}$ Shunt volume was also calculated using the stroke volume from left ventricular volumetry times the shunt fraction.

\section{STATISTICAL ANALYSIS}

Results were expressed as a mean (SD). Linear regression analysis was used to correlate PISA with other parameters. The difference between catheterisation and PISA measurements of shunt volume and shunt fraction were compared using the analysis of Bland and Altman. ${ }^{11}$ Student's $t$ test was used to compare the two groups. $P<0.05$ was considered statistically significant.

\section{Results}

VSD SHUNT ESTIMATION BY DOPPLER FLOW MAPPING AND CARDIAC CATHETERISATION The table shows the shunt flow variables obtained by both the PISA method using Doppler colour flow mapping and cardiac catheterisation. The SFR by the PISA method ranged from $22-302 \mathrm{ml} / \mathrm{s} / \mathrm{m}^{2}$ (mean $70(79)$ ). Shunt volume by the PISA method ranged from 7-78 ml/ $\mathrm{m}^{2}$ (mean $38(20)$ ) and by cardiac catheterisation it was $9-64 \mathrm{ml} / \mathrm{m}^{2}$ (mean 39 (15)). Shunt fraction by PISA ranged from $8-80 \%$ (mean $46(22)$ ) and by catheterisation it was $14-60 \%$ (mean $45(14)$ ).

CORRELATION BETWEEN THE PISA METHOD AND CARDIAC CATHETERISATION

A positive correlation $(r=0 \cdot 78, \mathrm{P}=0 \cdot 001)$ was demonstrated between shunt volume

Haemodynamic data assessed by PISA and cardiac catheterisation in 14 patients with ventricular septal defect

\begin{tabular}{|c|c|c|c|c|c|c|c|c|}
\hline \multirow[b]{2}{*}{ Case } & \multirow[b]{2}{*}{$\begin{array}{l}\text { Age } \\
\text { (years) }\end{array}$} & \multirow[b]{2}{*}{ Sex } & \multicolumn{3}{|c|}{ Cardiac catheterisation } & \multicolumn{3}{|c|}{ Doppler colour flow mapping (PISA) } \\
\hline & & & $\begin{array}{l}\text { Shunt } \\
\text { volume } \\
\left(\mathrm{ml} / \mathrm{m}^{2}\right)\end{array}$ & $\begin{array}{l}\text { Shunt } \\
\text { fraction } \\
(\%)\end{array}$ & $Q p: Q s$ & $\begin{array}{l}\text { Shunt flow } \\
\text { rate } \\
\left(\mathrm{ml} / \mathrm{s} / \mathrm{m}^{2}\right)\end{array}$ & $\begin{array}{l}\text { Shunt } \\
\text { volume } \\
\left(\mathrm{ml} / \mathrm{m}^{2}\right)\end{array}$ & $\begin{array}{l}\text { Shunt } \\
\text { fraction } \\
(\%)\end{array}$ \\
\hline 1 & 1 & $\mathbf{M}$ & 60 & 54 & $2 \cdot 3$ & 180 & 45 & 58 \\
\hline 2 & 1 & $\mathrm{~F}$ & 43 & 56 & $2 \cdot 5$ & 110 & 39 & 61 \\
\hline 3 & 0.8 & $\mathbf{M}$ & 41 & 55 & $2 \cdot 5$ & 122 & 29 & 34 \\
\hline 4 & 0.5 & M & 32 & 35 & $2 \cdot 4$ & 243 & 49 & 52 \\
\hline 5 & 6 & $\mathbf{M}$ & 18 & 22 & $1 \cdot 3$ & 33 & 10 & 8 \\
\hline 6 & 0.3 & $\mathbf{M}$ & 64 & 54 & $2 \cdot 7$ & 278 & 78 & 55 \\
\hline 7 & 3 & M & 9 & 14 & $1 \cdot 2$ & 22 & 7 & 8 \\
\hline 8 & 0.5 & $\mathbf{M}$ & 30 & 35 & 1.9 & 80 & 26 & 44 \\
\hline 9 & 2 & M & 30 & 40 & 1.8 & 88 & 21 & 33 \\
\hline 10 & 1 & $\mathbf{M}$ & 55 & 56 & $2 \cdot 4$ & 110 & 38 & 40 \\
\hline 11 & 0.6 & $\mathbf{M}$ & 38 & 46 & $2 \cdot 8$ & 302 & 60 & 62 \\
\hline 12 & 0.5 & $\mathbf{F}$ & 44 & 60 & $2 \cdot 5$ & 169 & 47 & 74 \\
\hline 13 & 1.5 & $\mathbf{M}$ & 45 & 52 & $2 \cdot 1$ & 143 & 37 & 80 \\
\hline 14 & 0.7 & $\mathbf{M}$ & 45 & 50 & $2 \cdot 1$ & 202 & 40 & 38 \\
\hline
\end{tabular}

Qp:Qs, pulmonary to systemic flow ratio. 
Figure 1 (Left) Diagram of the proximal isovelocity surface area. Measurement of the radius $R$ from the first aliasing to ventricular septal defect (VSD) is illustrated. (Right) Colour flow mapping of proximal isovelocity surface area.

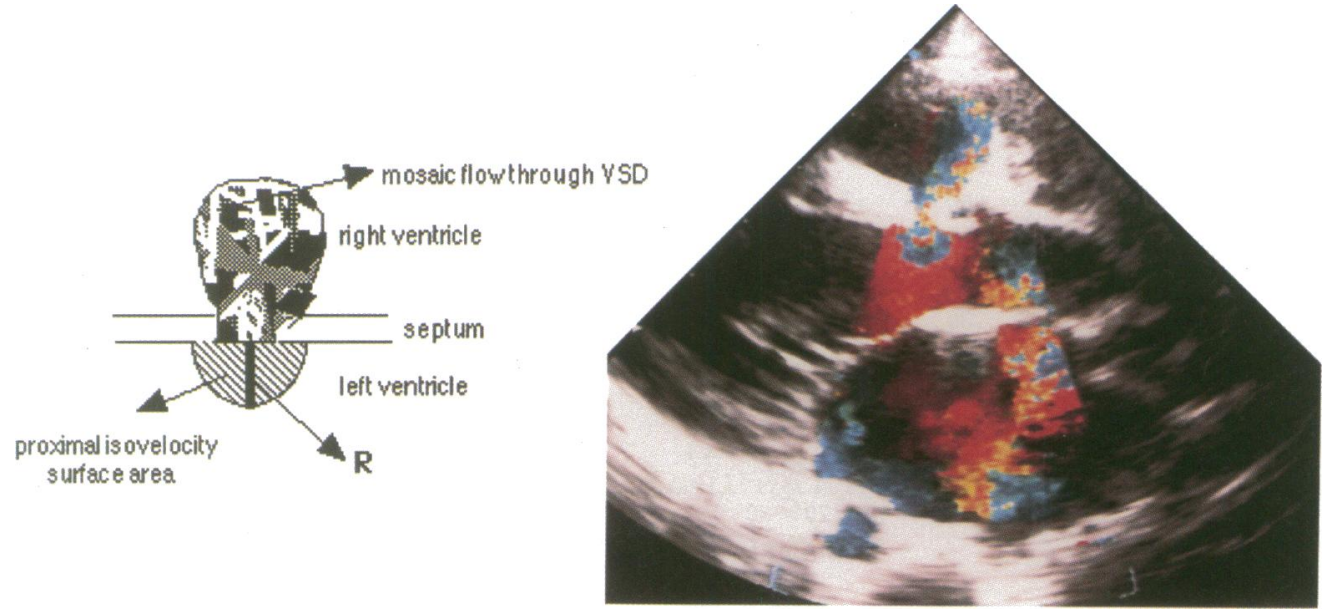

measured by the PISA method and by cardiac catheterisation (fig 2A). Standard error of the estimate was $10 \mathrm{ml} / \mathrm{m}^{2}$. The PISA method tended to underestimate shunt volume in patients with small or moderate shunts, and overestimate it in patients with large shunts compared with cardiac catheterisation (fig 2B). There was also a positive correlation $(r=$ $0.74, P=0.003$ ) between the shunt fraction by the PISA method and by cardiac catheterisation (fig 3A). Standard error of the estimate was $4 \%$. Again there was an overestimation using the PISA method in patients with large shunts and underestimation in patients with small shunts (fig 3B). The Qp:Qs by Fick ranged from $1.3-2.8$ (mean $2 \cdot 2(0.5)$ ). There was a significant correlation $(r=0 \cdot 79, \mathrm{P}=$ 0.0007) between SFR by PISA and Qp:Qs by Fick (fig 4). The SFR measured by the PISA method in all four patients with a Qp:Qs ratio $<2.0$ was less than $100 \mathrm{ml} / \mathrm{s} / \mathrm{m}^{2}$ (mean 54 (33)) and in all 10 patients with a $Q p: Q s$ ratio $>2.0$ it was greater than $100 \mathrm{ml} / \mathrm{s} / \mathrm{m}^{2}$ (mean 186 (69)) ( $P=0.004)$.

\section{REPRODUCIBILITY}

There was excellent inter- and intraobserver agreement for the calculation of SFR by PISA $(r=0.98$ for both). Intraobserver difference was $11(8) \mathrm{ml} / \mathrm{s} / \mathrm{m}^{2}$, and interobserver difference was $14(8) \mathrm{ml} / \mathrm{s} / \mathrm{m}^{2}$.

\section{Discussion}

The indication for surgical closure of a VSD is still determined by cardiac catheterisation findings in many institutions, although many non-invasive assessments for VSD have been reported. There are two important haemodynamic findings from cardiac catheterisation data guiding decision making for VSD closure: the magnitude of the VSD shunt volume and the pulmonary arterial pressure. Pulmonary artery pressure can be evaluated accurately by velocimetry of VSD flow on spectral Doppler tracing. However, quantitative estimation of VSD shunt flow has not yet been established, despite reports of non-invasive methods using cross sectional and spectral Doppler echocardiography. ${ }^{12} 13$ These methods have several methodological limitations, including a requirement for simultaneous measurements of valve diameters and flow velocity in both the aorta and pulmonary artery, and conversion of the valve diameter to flow area; processes which are very time consuming and are potential sources of error. In contrast, the PISA method allows quantitative assessment of VSD shunt flow more quickly and easily than previous methods, because VSD shunt calculation requires only measurements of area on one image of colour flow mapping and shunt duration on spectral Doppler recording. This makes the PISA method very practical
Figure 2 (A) Scatterplots showing the correlation of shunt volume measurement by the PISA method and by cardiac catheterisation. Dashed line is the line of identity. (B) Mean shunt volume between catheterisation and PISA measurements compared with the difference of the measurements. The mean measurements. The mean $\pm 2 S D$ from this difference (dashed lines) are shown.
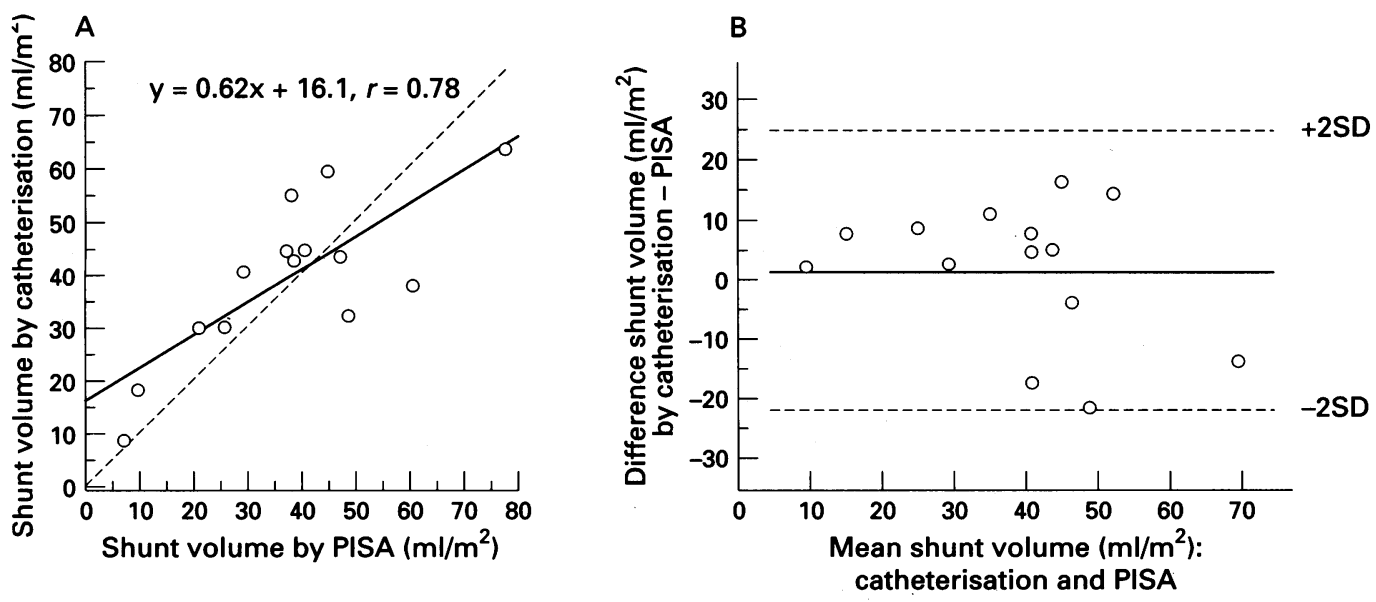
Figure 3 (A) Scatterplots showing the correlation of shunt fraction measured by the PISA method and by cardiac catheterisation. Dashed line is the line of fraction between measurements compared with the difference of the with the difference of the $\pm 2 S D$ from the difference (dashed line) are shown. identity. (B) Mean shunt catheterisation and PISA measurements. The mean

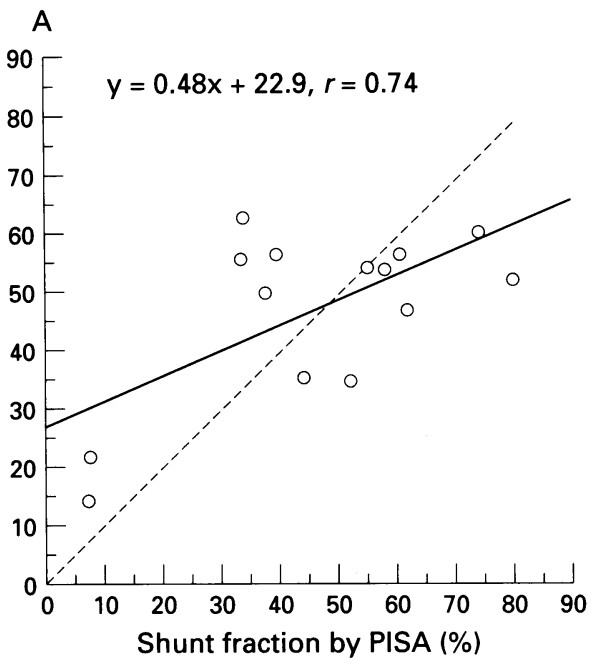

and simple compared with other non-invasive methods.

\section{ACCURACY OF PISA METHOD FOR VSD SHUNT ESTIMATION}

There were clinically useful correlations between the PISA and cardiac catheterisation methods of measuring shunt volume and shunt fraction. Additionally, we observed a significant correlation between SFR estimated by PISA and Qp:Qs, and other indices assessing the grade of left ventricular volume overload. ${ }^{14-16}$ However, SFR measured by the PISA method also has potential sources of error when measuring VSD shunt flow. To minimise this error we converted SFR to shunt volume by multiplying the SFR and shunt duration obtained from the Doppler flow velocity curve for VSD shunt flow. As a result, we obtained a linear correlation between PISA and cardiac catheterisation in quantifying VSD shunt volume and shunt fraction. This confirms that the PISA method has enough accuracy to estimate the grade of VSD shunt.

It is noteworthy that there was no overlapping values for SFR measured by PISA in

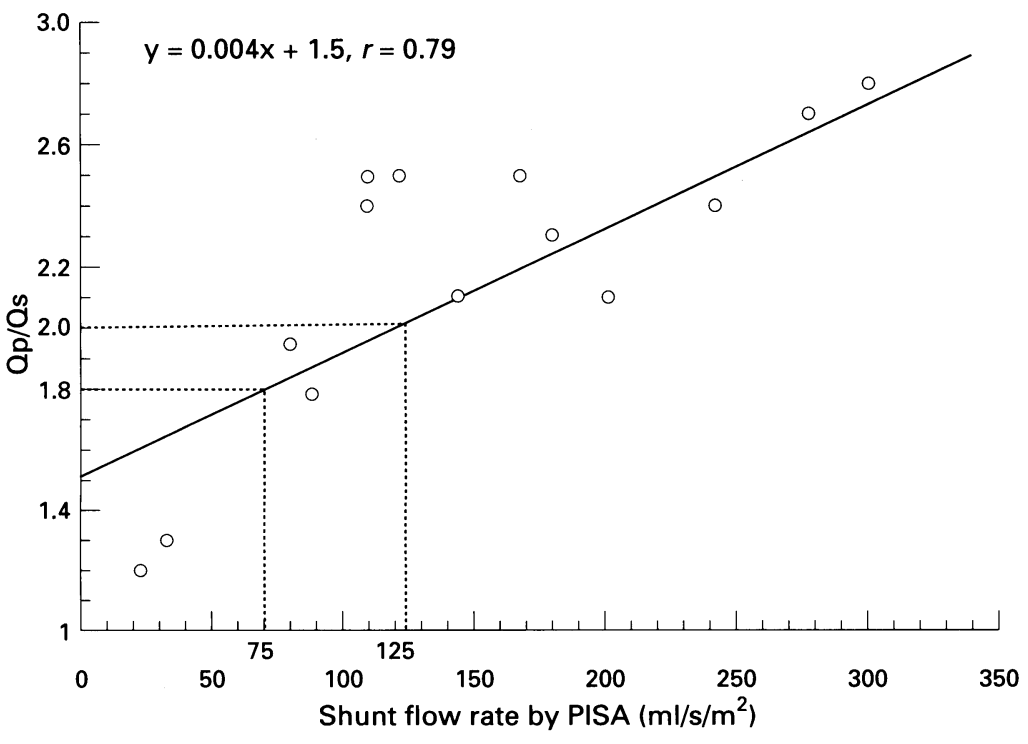

Figure 4 The relation between shunt flow rate measured by PISA and pulmonary to systemic flow ratio (Qp:Qs). There is no overlapping measurements of SFR between patients with a $Q p: Q s$ ratio of $<2 \cdot 0$ and $>2 \cdot 0$.

\section{B}

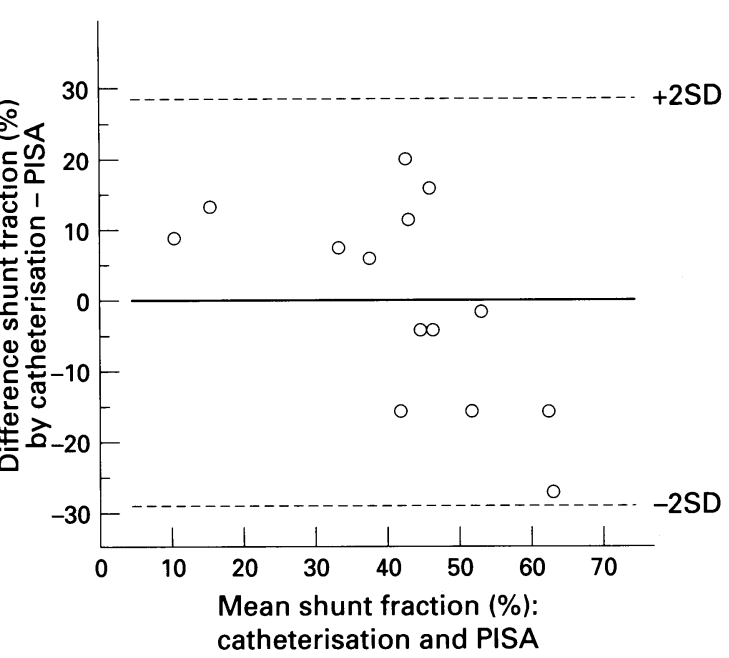

cases with Qp:Qs $<2 \cdot 0$ and $>2 \cdot 0$; however, our patient population was very small. The decision regarding surgical repair is frequently based on whether the Qp:Qs is $>2 \cdot 0$. Our data suggest that PISA is a reliable investigation for the quantitative assessment of VSD shunt flow and provides useful information for decisions regarding surgical repair.

\section{LIMITATIONS}

There are several potential sources of error in the measurement of PISA and the calculation of VSD shunt from Doppler colour flow mapping images. We used only one frame imaging maximum PISA per systole, therefore, the largest radius representing a maximal flow state was chosen to calculate VSD shunt flow. Theoretically, the shunt velocity profile and shunt duration is dependent on the pressure gradient between the left and right ventricle, therefore, PISA may change throughout the shunt duration. This study has shown that the PISA method tends to underestimate both the shunt volume and fraction in patients with small to moderate shunts, and to overestimate them in patients with large shunts. The use of the largest radius is probably the primary reason for overestimation of the VSD shunt in patients with a large shunt. On the other hand, in patients with a small to moderate shunt, the radius may not be maximal because of the relatively short shunt duration and varied VSD shunt profile during the shunt phase. Additionally, shunt estimation by Fick's principle during the cardiac catheterisation is not perfect. The use of relatively strong sedatives may alter the haemodynamics, particularly the pulmonary circulation. Sedation and/or mild anaesthesia can cause pulmonary vasodilatation, however, it can also cause hypercapnoeic pulmonary vasoconstriction, especially in small infants with high pulmonary flow and/or pulmonary hypertension. Thus, the fact that the echocardiography and catheter studies were done on separate days may have caused the error. These factors may explain the difference in VSD shunt variables by PISA method and cardiac catheterisation. Doppler colour flow mapping studies are usually performed without sedatives. The PISA method, there- 
fore, may represent more physiological VSD shunt magnitudes than those of cardiac catheterisation.

\section{CLINICAL IMPLICATIONS}

This study has shown the possibility of using echocardiographic assessment of VSD for determining whether surgical closure is required. An SFR of $100 \mathrm{ml} / \mathrm{s} / \mathrm{m}^{2}$ is the cut off point for VSD shunt magnitude, equivalent to a $\mathrm{Qp}: \mathrm{Qs}$ ratio of 1.9. In our institution, the criterion for surgical closure of a VSD without pulmonary hypertension has been a $\mathrm{Qp}: \mathrm{Qs}$ ratio of 1.8 by the Fick principle, ${ }^{17}$ which corresponds to a $75 \mathrm{ml} / \mathrm{s} / \mathrm{m}^{2}$ shunt flow rate by the PISA method. An SFR of $125 \mathrm{ml} / \mathrm{s} / \mathrm{m}^{2}$ is equal to a $\mathrm{Qp}: \mathrm{Qs}$ ratio of $2 \cdot 0$.

Multiple VSD is a difficult anomaly for surgical decision making as well as for clinical management. The PISA method may give further information in the assessment of multiple VSD. The PISA method may provide assessment of VSD shunt magnitude for each defect in patients with multiple VSD.

\section{CONCLUSIONS}

Our results suggest the ability of the PISA method to quantify shunt volume in patients with VSD. PISA can provide important information for decisions regarding surgical repair. Further study is required to confirm the reliability and accuracy of PISA.

1 Giesler M, Grossmann G, Schmidt A, Kochs M, Langhans $\mathrm{J}$, Stauch M, et al. Color doppler echocardiographic determination of mitral regurgitation flow from the proximal velocity profile of the flow convergence region. $\mathrm{Am} \mathfrak{F}$ Cardiol 1993;71:217-24.

2 Bargiggia GS, Tronconi L, Sahn DJ, Recusani F, Raisaro A, di Servi S, et al. A new method for quantitation of mitral regurgitation based on color flow doppler imaging of flow convergence proximal to regurgitant orifice. Circulation 1991;84:1481-9.

3 Yoshida K, Yoshikawa J, Yamamura Y, Hozumi T, Shakudo M, Akasaka T, et al. Value of acceleration flows and regurgitant jet direction by color doppler flow map- ping in the evaluation of mitral valve prolapse. Circulation 1990;81:879-85.

4 Utsunomiya T, Ogawa T, Doshi R, Patel D, Quan M, Henry WL, et al. Doppler color flow "proximal isovelocity surface area" method for estimating volume flow rate: effects of orifice shape and machine factors. $\mathcal{f} \mathrm{Am}$ Coll Cardiol 1991;17:1103-11.

5 Recusani F, Bargiggia GS, Yoganathan AP, Raisaro A, Valdes-Cruz LM, Sung H, et al. A new method for quanValdes-Cruz LM, Sung $\mathrm{H}$, et al. A new method for quantification of regurgitant flow rate using color doppler flow imaging of the flow convergence region proximal to a 594-604.

6 Schwammenthal E, Chunguang C, Benning F, Block M, Breithardt G, Levine RA. Dynamics of mitral regurgitan flow and orrifice area. Physiologic application of the proximal flow convergence method: clinical data and experimental testing. Circulation 1994;90:307-22.

7 Moises VA, Maciel BC, Hornberger LK, Murillo-Olivas A, Valdes-Cruz LM, Sahn DJ, et al. A new method for noninvasive estimation of ventricular septal defect shunt flow by Doppler color flow mapping: imaging of the lamina flow convergence region on the left septal surface. $\mathcal{F} A m$ Coll Cardiol 1991;18:824-32.

8 Teicholtz LE, Kreulen T, Herman MV, Gorlin R. Problems in echocardiographic volume determinations: echocardiographic - angiographic correlations in the presence or absence of asynergy. Am 7 Cardiol 1976;37: 7-11.

9 Dodge HT, Sandler HT, Ballew DW, Lord JD. The use of biplane angiography for the measurement of left ventricular volume in man. Am Heart $₹ 1960 ; 60: 762-76$.

10 Krovetz LJ, Goldbloom S. Normal standard for cardiovascular data. fohns Hopkins Med f 1972;130:174-86.

11 Bland J, Altman D. Statistical methods for assessing agreement between two methods of clinical measurement. Lancet 1986;i:307-10.

12 Sanders SP, Yeager S, Williams RG. Measurement of systemic and pulmonary blood flow and $\mathrm{Qp}: \mathrm{Qs}$ ratio using doppler and two-dimensional echocardiography. $\mathrm{Am} \mathcal{J}$ Cardiol 1983;51:952-6.

13 Barron JV, Sahn DJ, Valdes-Cruz LM, Lima CO, Goldberg SJ, Grenadier E, et al. Clinical utility of twodimensional doppler echocardiographic techniques fo estimating pulmonary to systemic blood flow ratios in children with left to right shunting atrial septal defect ventricular septal defect or patent ductus arteriosus. $\mathscr{F}$ Am Coll Cardiol 1984;3:169-78.

14 Lewis $A B$, Takahashi $M$. Echographic assessment of left to right shunt volume in children with ventricular septal defect: Circulation 1976;54:78-82.

15 Lester LA, Vitullo D, Sodt P, Hutcheon N, Arcilla R. An evaluation of the left atrial/aortic root ratio in children with ventricular septal defect. Circulation 1979;60: with ven $364-72$.

16 Baylen BG, Meyer RA, Kaplan S, Ringenburg WE Korfhagen J. The critically ill premature infant with patent ductus arteriosus and pulmonary disease-an patent ductus arteriosus and pulmonary disease-an

17 Nakada T. Studies on pulmonary circulation in congenital heart diseases with left to right shunt; a proposal of functional classification based on the pulmonary vascula resistance. $\mathscr{f} \mathcal{F} A T S$ 1967;15:1013-33. 